\title{
REFLEXIONES EN TORNO A LA FUNCION PUBLICA CHILENA
}

\author{
POR \\ Federico A. Castillo Blanco \\ Técnico de Administración General \\ Profesor Asociado del Departamento de Derecho Administrativo \\ de la Universidad de Granada
}

SUMARIO: I. El municipio chileno enclavado en la organización territorial del estado.-II. Clases de personal y régimen jurídico.-III. El estatuto jurídico del funcionario municipal chileno: plan de acción cívica nacional.-IV. Aproximación a las claves de una futura regulación del personal municipal chileno. - V. Conclusiones (1).

\section{EL MUNICIPIO CHILENO ENCLAVADO EN LA ORGANIZACION TERRITORIAL DEL ESTADO}

El origen del municipio chileno, al igual que en la mayoría de lberoamérica se remonta a los cabildos municipales del período colonial, ahora bien hasta la fecha del golpe militar de 1973 habian constituido entes públicos democráticos de la Comuna chilena.

En este sentido su organización institucional (Cuerpo de Regidores) era renovado cada tres años mediante sufragio popular y directo, estableciéndose un sistema de elección de segundo grado para la elección del Alcalde. La participación ciudadana en el ámbito políticoadministrativo era completada a través de dos tipos de organizaciones (Ley 16.880 de 1968):

- Organizaciones comunitarias territoriales (juntas de vecinos).

- Organizaciones comunitarias funcionales (centros de madres, cooperativas, grupos de viviendas, etc.).

No obstante, como destaca Jordi Borja (2) «La debilidad de los Gobiernos locales en América Latina es' hoy una de las causas principales del carácter limitado y precario de la Democracia. La organización municipalista española nunca se implantó plenamente y los Estados nacidos de la independencia anularon a los municipios,

(1) El presente estudio-extracto es fruto del Primer Proyecto de Cooperación Técnica Municipal, que auspiciado por el Instituto de Cooperación Iberamericana y el Centro de Estudios Municipales y de Cooperación Interprovincial de Granda se desarrolló en Chile en el verano de 1988, con la colaboración inestimable de la ONG chilena «Cordillera».

(2) Borja, Jordi: Manual de Gestión Municipal Democrática. Instituto de Estudios de Administración Local. Madrid, 1987. 
tanto por ser reductos de las oligarquías locales como por su inadecuación para la prestación de los servicios públicos modernos. Incluso en los Estados formalmente federales el rol y la autonomía de los Gobiernos regionales y locales no equilibran el acentuado centralismo político-administrativo. Los ejecutivos locales raramente proceden de la elección popular y adolecen de poca representatividad y legitimidad democráticas. La experiencia de gestión es pobre y es bajo el nivel de la Función pública local, en la mayoría de los casos. Los políticos y profesionales más cualificados prefieren ocupar puestos en el Estạdo, en la Administración central, de más prestigio y que, en gran parte, ejercen las competencias decisorias que idealmente corresponden a los Gobiernos locales. La insuficiencia de recursos de éstos (entre el 5 y 10 por 100 del gasto público en la mayoría de los países) y la baja productividad de unas Administraciones hinchadas de personal y tecnológicamente atrasadas constituyen hoy obstáculos prácticamente insuperables para una actuación pública eficaz».

De acuerdo con ello, somos de la opinión de que dicho modelo centralizado no va a dar respuestas a la democratización del Estado, pues como señala este mismo autor, éste centraliza inevitablemente los conflictos sociales. En este sentido se presenta hoy como una necesidad ineludible, la descentralización de las estructuras estatales y el reforzamiento de los Gobiernos locales, para aprovechando el marco favorable que actualmente vive Iberoamérica con respecto a la democratización de sus estructuras políticas, afianzar dichos procesos y garantizar una mayor participación ciudadana, un acercamiento en la toma de decisiones, que redunde en una mayor eficacia administrativa $y$, en definitiva, conseguir una representatividad real de las instituciones políticas.

Chile no ha vivido al margen de dicho proceso y así las municipalidades chilenas han actuado con grandes limitaciones, incluso hasta el año 1973. Así:

- No había una completa democratización de las estructuras locales: los Alcaldes de Valparaíso, Santiago y Concepción eran designados directamente por el Presidente de la República.

- Las competencias municipales eran reducidas y de poca importancia cualitativa.

- En tercer lugar, no estaba garantizado el Principio de Autonomía frente al poder central ni el necesario reconocimiento $y$ protección del Principio de Suficiencia Financiera que posibilitará a los municipios chilenos los recursos necesarios para efectuar un efectivo ejercicio de las competencias municipales. 
Es en este contexto donde surge la reforma territorial del Estado incardinado en dos sucesivos procesos: el de regionalización (19741980) y el de municipalización (1980-1987), este último inserto en el Programa de Modernizaciones. Encuentran su base jurídica en los Decretos leyes 573 y 575 de 1974, que al decir de José AyLwin (3) tienen como objeto abrir nuevos espacios para el desarrollo de la iniciativa privada (modelo de libre mercado. Tesis neoliberales de la Escuela de Chicago) y de lograr un mayor control político de la población (doctrina de la seguridad nacional) y así reorganizar la Administración del Estado dividiendo el país en Regiones, éstas en Provincias y estas últimas en Comunas.

Por su parte el proceso de municipalización amén de algunos antecedentes como el Decreto ley 3063 de 1979 (Ley de Rentas Municipales), el DFL 3063 de 1980 (que reglamenta los traspasos de servicios a los municipios) y el Decreto ley 3477 de 1980 (que faculta a los municipios a transferir los servicios traspasados por el Estado a Corporaciones privadas sin fines de lucrol, se va a concretar en la Ley 18695 de 1988 de Municipalidades.

En este sentido el proceso de reforma territorial del Estado, tiene como señala ArLwin dos objetivos fundamentales:

a) En lo económico, hacer efectivo el Principio Económico Liberal de la subsidiariedad del Estado, buscando abrir espacios, tanto a nivel regional como local, que den acceso al sector privado a sectores públicos de tanta trascendencia social como la enseñanza y la sanidad.

b) En lo político, sustituir las fórmulas representativas y de participación directa democrática por una compleja trama de representación a través de los Comités Regionales de Desarrollo (COREDES) y los Consejos de Desarrollo Comunal (CODECOS), que en definitiva intentan impedir la elección directa de las autoridades locales por los ciudadanos perpetuando un régimen autoritario y de control directo por parte de las autoridades centrales y que burla la pretendida «descentralización»y «democratización» que dice pretende implantar.

Por ello, un análisis de la legislación vigente en Chile en estos momentos permite llegar a una serie de conclusiones y definir una serie de Principios inspiradores de la reforma administrativa chilena:

a) Ausencia total del Principio de Autonomía Municipal, lo cual queda palmariamente descrito en el artículo 7 de la Ley 18695, que va a establecer «las municipalidades deberán actuar, en todo caso, dentro del marco de los planes nacionales y regionales que regulen la

(3) Aylwin Oyarzun, Jose: La Reforma Municipal: un mecanismo para la proyección del régimen. Santiago de Chile, 1988. 
respectiva actividad» o en el artículo 64 al decidir los COREDES, las personas naturales o jurídicas que realicen actividades relevantes y que como consecuencia tendrán derecho a participar en la designación de representantes en los CODECOS, órgano, como aludíamos, de representatividad municipal.

b) Sustitución del Principio de Autonomía Local por el Principio de Jerarquía Administrativa, toda vez que es posible establecer una línea de sumisión desde el Presidente de la República, pasando por el Ministro del Interior, el Intendente Regional, el Gobernador Provincial, hasta llegar al Alcalde, y dado que la gestión de sus intereses respectivos - en cada comuna - no se decide a nivel comunal, pues éstas como establece el artículo 7 de la meritada disposición legal, actúan dentro del marco de los Planes Nacionales y Regionales, que vienen marcados por ODEPLAN a nivel nacional, la SERPLAC regional y la SERPLAC provincial hasta llegar a nivel comunal.

c) Anulación de la participación ciudadana y ello en base a las siguientes consideraciones:

- La forma antidemocrática de constitución de los COREDES y CODECOS, como destaca Jorge Martelli (4).

- La no regulación de instituciones que permitan a las organizaciones sectoriales y territoriales una efectiva participación y debate en los asuntos e intereses que le son propios.

- El intento de eliminar toda participación política y su sustitución por una aparente Democracia y en este sentido los miembros de los CODECOS cesan en sus cargos según el artículo 74.f de la Ley de Municipalidades por «inhabilidad declarada por el Tribunal Regional competente motivado por haber cumplido órdenes o recomendaciones de un partido político en materias atinentes al desempeño de su cargo".

d) La eliminación "semiabsoluta» del «Estado de Bienestar» y su sustitución por un Estado completamente subsidiario presidido por un criterio economicista que no está posibilitando, hoy por hoy, otra cosa que restringir el acceso de la ciudadanía chilena en condiciones de igualdad a servicios tan esenciales como la enseñanza o la sanidad.

Por ello, empezábamos estas líneas afirmando la debilidad de los Gobiernos locales en Iberoamérica y presentábamos la necesidad de su fortalecimiento para robustecer el principio democrático y participativo de los ciudadanos en la vida pública. En este sentido el proceso

(4) Martell Robba, Giorgio: La nueva ley de municipalidades ¿Democracia a nivel local? Santiago de Chile, 1988. 
de reforma municipal chilena no viene inspirado por una auténtica descentralización que otorgue a entes públicos dotados de autonomía la gestión propia y autónoma de sus competencias, sino por una "desconcentración encubierta» por la que los municipios pasan a ser en última instancia una ramificación de la estructura estatal que persigue un mayor control político-social de la población, de acuerdo con la doctrina de la seguridad nacional.

Es en este contexto, donde se sitúan las competencias de los municipios chilenos, reguladas en la Ley 18695 en sus artículos 2 y 3 y que permiten realizar la siguiente clasificación:

- Competencias privativas (aseo y ornato de la comuna, confección del Plan regulador comunal...).

- Competencias ejercidas directamente o en coordinación con órganos de la Administración del Estado (Salud, Educación, Construcción de viviendas sociales, turismo...) y que constituyen las realmente relevantes $y$ en donde el Municipio actúa subordinado a los Planes Nacionales y Regionales.

\section{CLASES DE PERSONAL Y REGIMEN JURIDICO}

A fin de atender las competencias atribuidas a las comunas chilenas, y como en toda organización administrativa ocurre, se hacen precisos una serie de medios económicos, materiales y personales, y así el Profesor VARA (5) ha puesto de relieve estos últimos como elementos dinamizadores del municipio en la etapa actual de cambio democrático en Chile.

De acuerdo con la regulación legal, podemos distinguir las siguientes clases:

a) Personal de carácter político: los Alcaldes.

Estos, de acuerdo con el artículo 32.2 de la Ley 18695, son funcionarios municipales, aunque establece y añade su párrafo 3. que sólo les serán aplicables a éstos las normas relativas a derechos, deberes y responsabilidad administrativa.

Su elección se produce por el Consejo de Desarrollo Comunal (CODECO) quien elabora una terna al Consejo Regional de Desarrollo (COREDES) de la cual éste designa al Alcalde. No obstante, esta terna puede ser vetada por el Intendente Regional, en cuyo caso se repite el mecanismo, no pudiendo ser de nuevo objeto de veto (art. 48 Ley 18695). No obstante este procedimiento, en las 16 comunas más 1988.

(5) VARA, Carlos: Personal municipal chileno: problemas y perspectivas. Santiago de Chile, 
importantes del país, el Alcalde, es designado directamente por el Presidente de la República.

De otro lado el sistema municipal potencia la figura del Alcalde en quien concentra las más importantes funciones cuantitativa $y$ cualitativamente dentro de los órganos municipales, configurando un sistema claramente presidencialista y de concentración de poderes en lo que podríamos denominar analógicamente y en comparación con el Estado «Poder ejecutivo» a similitud de lo que la Constitución Política Chilena de 1980 hace con el Presidente de la República (art. 53 Ley 18695).

No obstante, es necesario considerar que técnicamente parece desaconsejable, y ello deberá tenerse en cuenta en el futuro democrático de Chile, la equiparación con funcionario público del personal político. En el fondo parece subyacer el intento de «desideologización» y de «tecnocratización» que se pretende imprimir a la vida pública y participativa chilena.

Desde otros parámetros y desde otro punto de vista parece más coherente la elaboración de un estatuto de miembros de las municipalidades que garantice sus derechos, deberes, régimen retributivo, régimen sancionador, responsabilidad civil y penal, etc. sin intentar confundir al funcionario público, con un carácter permanente y de servicio al interés público de forma neutral, con el personal de carácter político con un carácter contingente y que imprime en su acción pública la fijación de metas y objetivos de acuerdo con una ideología.

b) Los funcionarios municipales.

Nos referimos en este caso a los funcionarios municipales, propiamente tales, integrados dentro de las plantillas orgánica municipales y que viene organizado jerárquicamente en escalafones.

Supone unos 20.000 en el conjunto de las 320 municipalidades del país. Este personal de acuerdo con la disposición transitoria tercera de la Ley 18.695 seguirá rigiéndose por las normas estatutarias actualmente en vigor que están constituidas por:

- DL 1289 de 1976 (la parte dedicada a personal municipal).

- DFL 338 de 1960 (Estatuto Administrativo).

Se caracteriza fundamentalmente este tipo de personal por la ausencia total y absoluta de un sistema, ya sea de carrera o de empleo, que determine su regulación homogénea.

Más bien parece imperar como más adelante aludiremos, el denominado tradicional «spoils sistems» o «sistema de botín» en que se prima de forma fundamental la fidelidad política. 
c) El personal traspasado o «transferido" de servicios que han pasado a depender de las municipalidades.

Este tipo de personal que supone unas 100.000 personas viene regulado fundamentalmente por dos tipos de normas: el DL 3063 y DFL 1-3063, siendo su característica fundamental que al ser transferidos su régimen jurídico pase del Derecho administrativo al laboral a similitud con las empresas privadas, al pasar a depender de Corporaciones creadas por las municipalidades.

d) El personal que recibe los subsidios PEM, POMJ y PIMO y que supone según el Profesor Carlos VARA (6) un contingente de alrededor de 200.000 personas y que a cambio de un subsidio deben realizar trabajos de utilidad comunal.

\section{EL ESTATUTO JURIDICO DEL FUNCIONARIO MUNICIPAL CHILENO: PLAN DE ACCION CIVICA NACIONAL}

El análisis de este epígrafe puede venir presidido por la afirmación de la inexistencia en Chile de un sistema de Función pública, ya sea abierto o cerrado, que haga al funcionario público una institución eficaz al servicio de los intereses generales, dada la arbitrariedad, que no discrecionalidad, en su regulación jurídica actual, que tiende a hacer del funcionario una pesona sumisa y obediente al servicio de la continuidad del régimen militar si no quiere ver peligrar su puesto de trabajo.

De esta forma se puede concretar la anterior afirmación en los siguientes puntos:

a) No existe un acceso objetivo a la función pública, que a través de un proceso selectivo asegure el ingreso en la Administración pública de las personas más capacitadas e idóneas, que de forma neutra o imparcial accedan al servicio del interés público.

b) Tampoco se han establecido normas que regulen la carrera administrativa, es decir, la posibilidad de ascenso dentro de la estructura burocrática, ya sea a través de la promoción interna (entendiendo por éste el acceso del personal de escalas inferiores a otras superiores) o a través de desempeñar puestos de trabajo de mayor responsabilidad dentro de la misma escala.

c) Tampoco se reconoce, lo que técnicamente se ha denominado como derecho al cargo, es decir, la imposibilidad de remoción de un funcionario público, salvo por motivos disciplinarios, to cual es

(6) Vara, Carlos, op. cit. 
inherente a un sistema de estatuto o cerrado, en el cual los derechos $y$ obligaciones del funcionario no nacen de un contrato, sino que devienen de forma directa de la Ley. Derecho al cargo que implica además el derecho a ejercer unas determinadas funciones y no otras y que puede ser absoluto (cuando conlleva la inamovilidad, es decir, el desempeñarlo en un determinado lugar) o relativo cuando no conlleva tal inamovilidad.

Del no reconocimiento de este derecho básico dimana que la remoción de un funcionario público puede hacerse libremente aunque éste cumpla de forma estricta y eficaz sus funciones, por la sola voluntad subjetiva del Alcalde.

d) De otro lado y a pesar de la anterior evidente desprotección de este funcionario público, tampoco le está reconociendo el derecho de sindicación y huelga y el derecho de participar en la negociación de sus condiciones de trabajo.

e) Esta situación anárquica y arbitraria, típica del «sistema de Botín» y que no conduce a una función pública profesionalizada y moderna se ve agravada por una característica común a la mayoría de los países, consistente en la tradicional discriminación del funcionario municipal frente al funcionario estatal o regional, trato discriminatorio difícilmente justificable y que consagra dentro del Estado a funcionarios de primera clase y a funcionarios de segunda. Tan grave distinción debería ser erradicada del sistema, consagrando un Estatuto administrativo, en su sentido material y no formal, que asegure unos contenidos básicos mínimos para todos los funcionarios chilenos, ya sean éstos estatales, regionales o municipales sin perjuicio de las singularidades propias de cada organización que habrán de ser respetadas.

f) Junto a estos factores también cabe aludir al «cuasi procesamiento" a que se ve sometido anualmente cada funcionario a través del sistema de calificaciones, en virtud del cual anualmente una "Junta Calificadora" compuesta por los cinco funcionarios de más alta categoría y un representante del personal «designado de acuerdo al procedimiento y modalidad establecidos por el Ministerio del Interior» valoran anualmente la actuación de cada funcionario, basándose en cuatro factores:

1. Idoneidad

2. Disciplina

3. Conducta

4. Cultura

que determina, caso de no obtener unas puntuaciones mínimas, su retirada del servicio. 
Este sistema puede conducir en la práctica (no se olvide que estos funcionarios, de alta categoría, han sido seleccionados con arreglo al criterio de la voluntad subjetiva del alcalde y que el procedimiento de valoración y los factores valorables por su naturaleza son subjetivos) a una continua «depuración» no del personal no capacitado, sino del personal no afín por motivos políticos o personales.

g) Lo anteriormente expuesto viene palmariamente descrito en el Decreto ley 3351 de 1980, que en su artículo 22 va a establecer:

«Los empleados de las municipalidades, con excepción de los jueces de Policía Local, serán de la exclusiva confianza del alcalde, quien podrá nombrarlos, promoverlos y removerlós con entera independencia de toda autoridad.»

O en el Plan de Acción Cívica Nacional que en el capítulo denominado «Frente de difusión doctrinaria y de capacitación de líderes» establece como criterios para la selección del personal:

a) Grado de adhesión al Gobierno

b) Formación Profesional

c) Capacidad de acción

d) Espíritu de entrega.

O en el capítulo denominado "Análisis de los actores y tendencias políticas locales» se va a señalar:

«Los municipios cuentan con recursos humanos, materiales, financieros y de planificación. En la comuna existen igualmente servicios sectoriales de Gobierno. Estos recursos no deben ser empleados con un criterio de coyuntura o un mero sentido administrativo. Ellos son la base para consolidar el carácter fundacional del régimen y proyectarlo más allá de 1989.

Es por ello necesario, en cuanto al personal, revisar permanentemente las lealtades y el compromiso doctrinario y en cuanto a la inversión privilegiar al buen sentido político, capitalizando la obra del Gobierno en cada comuna.»

De lo expuesto se deduce que no está hoy configurada en Chile una Función pública moderna, al servicio no, de unos intereses ideológicos, sino del interés general de la ciudadanía -en la cual radica la soberanía nacional- en que se haya regulado de manera objetiva los contenidos mínimos de regulación de un sistema de Función pública en que se prime el mérito y la capacidad como principios dinamizadores de la misma, antes bien los párrafos recogidos demuestran la clara voluntad del Gobierno chileno de tener 
funcionarios sumisos y subordinados, que carezcan de garantías en el desarrollo de sus funciones.

\section{APROXIMACION A LAS CLAVES DE UNA FUTURA REGULACION DEL PERSONAL MUNICIPAL CHILENO}

\section{Los sistemas abiertos y cerrados de Función pública}

Se ha de partir de la afirmación ya anteriormente expresada de que una regulación del personal municipal chileno, no cabe desprenderlo o aislarlo de una regulación general de la Función pública estatal y regional, pues resulta cuando menos conveniente que el sistema de Función pública que se diseñe sea homogéneo en todos sus grados territoriales. Por tanto, parecerá interesante englobar la reforma del personal municipal dentro del diseño de una reforma de la Función pública, en general, de Chile que evite diferencias de trato y discriminación, de los que, en definitiva, tienen un rasgo común: ser servidores públicos.

Por ello parece orientativo pasar a describir los sistemas de Función pública hoy imperantes en la mayoría de los países, que nos posibilite el tener un marco de referencia para el análisis del personal municipal chileno. Desde este punto de vista las soluciones que cada país ha establecido para dar respuesta a los problemas, se pueden agrupar en sistemas abiertos o cerrados (7), según estén más o menos próximos al sistema laboral común. Es decir, se trata de contraponer el sistema público con el privado y deducir la existencia - la consecuencia de un sistema de Función pública diferente al laboral privado.

\section{A) Sistema de Función pública abierta o sistema de puesto de trabajo}

Este sistema se basa en un inventario previo muy preciso de los puestos de trabajo, como se hace en las empresas privadas limitándose la Administración a seleccionar las personas adecuadas que, frecuentemente, provienen del sector privado. Este es el modelo teórico de Estados Unidos, toda vez que el Estado americano carece de tradición estatal, se estructura sobre principios democráticos no burocráticos y considera que la gestión de la Administración pública no debe ser diferente a la de las empresas privadas.

Además, la existencia de grandes empresas facilita el intercambio laboral entre el sector público y el privado.

De esta forma la Administración no tiene que ocuparse de la formación de los funcionarios, sistema de ascensos, situaciones

(7) Gazier: La Fonction publique dans le monde. París, 1972. 
administrativas, etc. El personal que trabaja en la Administración es despedido cuando su puesto sea innecesario o no sea desempeñado con la competencia exigida.

La relación es generalmente de contrato laboral y los conflictos son resueltos por la justicia ordinaria.

La flexibilidad y la rentabilidad son las notas características de este modelo (8).

No obstante, cabe hacer las siguientes reflexiones:

1. La Administración pública no es una empresa privada y la rentabilidad no debe ser su objetivo a perseguir con las características del sector privado. En la Administración pública el fin primordial es el interés general que debe primar sobre cualquier oira consideración. Como señala el Profesor NiETo «La integración de las modernas técnicas de gestión en la Administración pública nunca podrá producirse en la misma manera que en las empresas privadas por cuanto la naturaleza pública de la institución, el que la razón política predomine sobre la racionalidad técnica, hace que muchos progresos técnicos, utilizados con éxito habitualmente en las empresas privadas, no puedan serlo en la Administración pública, pues podrían distorsionar principios como el de igualdad, imparcialidad y legalidad, muy distintos al de la eficacia y el lucro que son motores fundamentales que mueven el sector privado (9).

2. En segundo lugar falta la experiencia progresiva y la ausencia de un aprendizaje que permita el acceso a puestos de trabajo superiores.

3. Por último, no puede olvidarse que este sistema exige como indica Gazier (10):

- La existencia en el país de un régimen de enseñanza que proporcione personal altamente cualificado y especializado.

- Un sector privado desarrollado que permite el intercambio de personal, condiciones que, no se olvide, no existen en todos los países.

En definitiva, la idea clave de este sistema es la del puesto de trabajo que puede ser definidio como la unidad estructural básica, integrada por el conjunto de tareas y responsabilidades asignadas por la autoridad competente a una persona, lo que, lógicamente, exige que posea una cantidad suficiente para necesitar la actividad de una

(8) De la Cruz Ferrer: La Función Pública Superior en Estados Unidos. Madrid, 1984.

(9) Nieto, Alejandro: Documentación Administrativa núm. 200, 1984.

(10) Op. cit. 
persona durante la jornada laboral y así se caracteriza por las siguientes especialidades:

1. La realización del reclutamiento para un puesto especial determina la exigencia de una experiencia previa en el desempeño de las funciones.

2. Se da preferencia en la selección a pruebas de tipo «práctico», entendiéndose por tales las que permitan determinar qué aspirante puede hacerse cargo con más competencia del puesto de trabajo por el que se compite.

3. No existe la nota de permanencia, lo cual permite una gran flexibilidad al sistema, pudiendo adaptarse los efectivos de personal a las necesidades de los programas presupuestados.

4. Se hace innecesaria la regulación de una carrera administrativa, proceder a la formación de funcionarios, etc.

\section{B) Sistema de Función pública cerrado o sistema de carrera}

En éste la persona que ingresa en la Administración pública, después de superar las diferentes pruebas de ingreso, entran en un cuerpo general o especial, normalmente jerarquizado, en el que pueden ascender desde los últimos niveles hasta los de más categoría.

El ascenso se posibilita a través de la antigüedad, méritos o capacidad y la relación de empleo es, en principio, permanente.

El elemento fundamental de este sistema es, en primer lugar, la posibilidad de contar con personal más cualificado, con una experiencia superior adquirida desde la iniciación al servicio, un perfeccionamiento adecuado a las funciones públicas y una continuidad asegurada en el desempeño de la Función pública dada la permanencia.

El modelo es, sin embargo, más rígido, pues cuando una clase o número de servicios resultan innecesarios no se puede prescindir de sus titulares, sino que deben readaptarse a otros. Existe también el peligro de la burocratización excesiva, la rutina y una menor rentabilidad.

El régimen jurídico de este sistema es el Derecho administrativo y no el laboral y sus características principales la exigencia de un estatuto especial y la jerarquización.

Sus características principales son así, dado el Principio de Estabilidad en el empleo que impera y el carácter cerrado del mismo:

1. El comienzo en el Servicio se produce en edades muy jóvenes, con exclusión de reglas excepcionales o de personas que, por méritos 
excepcionales, ingresan en la Administración pública después de una experiencia profesional muy valiosa.

2. Existe un sistema de requisitos individuales y de exámenes que en algunos países se completa con la realización de un curso en «Escuelas» y con un período de prácticas.

3. Se articula una carrera administrativa basada en una promoción por grados que descansa sobre el mérito comparativo, la antigüedad y una valoración de los servicios prestados. La efectividad de la promoción está en función de factores muy diversos, a los que hay que añadir el grado de politización del aparato burocrático. Por regla general, los sistemas de promoción afectan, negativamente, a los poseedores de un cierto espíritu de empresa en favor de las personas capaces de trabajar en equipo y de manifestar un práctico espíritu de compromiso.

4. Existe cierta incomunicabilidad entre los sectores privado y público, lo cual fue criticado por el Informe Fulton (11).

5. La rigidez del sistema de carrera obliga a la necesidad de establecer programas concretos de formación y adiestramento, ya que la Administración debe utilizar sus medios personales, adaptándolos tanto a las meras actividades y servicios que presta como a las innovaciones tecnológicas que permitan la mejora en el desempeño de las funciones públicas tradicionales.

Ahora bien, entre ambos existen sistemas mixtos, pues es difícil que se den en estado puro y generalmente todos los modelos de Función pública adscribiéndose a uno u otro admiten elementos ajenos. Así, por ejemplo, en el sistema español que partiendo de un sistema cerrado se orienta, primero con la reforma 1963/1965 y posteriormente con la Ley de Medidas para la Reforma de la Función pública de 2 de agosto de 1984, hacia un sistema abierto.

Por ello es necesario para cualquier país plantearse al diseñar su Función pública a qué sistema quiere orientarse, teniendo en cuenta como indica Gregorre (12) que la elección de uno u otro depende básicamente, del papel que realice el Estado en la vida nacional, papel que en el sistema de carrera atribuye al empleado unas especiales características de «poder público» que lo distinguen de cualquier profesional que desempeña las mismas actividades en el sector privado.

(11) Comite Fulton. ENAP, 1973.

(12) Gregoire, Roger: La fontion publique... París, 1954. 
En esta misma línea Parada Vazouez (13) señala que se han de tomar posiciones en una serie de problemas, entre los que pueden señalarse como más significativos:

- ¿La formación de los funcionarios debe hacerse en escuelas propias de la Administración o basta con la instrucción del sistema educativo? ¿Debe primar la especialización sobre los conocimientos generales o viceversa?

- La Función pública, ¿ha de gestionarse a través de órganos centrales o departamentales, colegiados o unipersonales?

- Los funcionarios ¿deben integrarse en cuerpos o carreras jerarquizadas, o basta con la vinculación a un determinado puesto de trabajo?

- Sobre qué postulados deben organizarse las relaciones del funcionario con la política: ¿el cambio político determina la destitución de unos funcionarios por otros (spoils sistem), o no afecta a las relaciones de empleo?, cel funcionario debe adoptar una actitud de neutralidad política o puede participar en ella afiliándose a un partido, y aceptando nombramientos políticos?

\section{La Ley Orgánica Constitucional de municipalidades, análisis y valoración}

De acuerdo con lo anteriormente expuesto esta Ley sitúa a la Función pública municipal chilena dentro de un esquema o sistema cerrado de Función pública.

Efectivamente, el personal municipal chileno regulado en la Ley 18695 (art. 32 a 40) se integra en un sistema basado en un Estatuto, un cuerpo y una carrera, que a decir de Parada Vazouez (14) son los tres elementos fundamentales que configuran este sistema y así:

a) El Estatuto general que impone a los funcionarios mayores deberes y responsabilidades que al personal privado, viene recogido en el artículo 32.1 al establecer:

«El Estatuto administrativo de los funcionarios municipales regulará la carrera funcionaria y considerará especialmente el ingreso, los derechos y deberes, la responsabilidad administrativa y la cesación de sus funciones."

(13) Parada Vazouez, Jose Ramon: Organización y Empleo Público. Editorial Marcial Pons. Madrid, 1988.

(14) Op. cit. 
b) El cuerpo y la carrera se recogen en el artículo 34 al establecer su párrafo primero:

«El personal estará sometido a un sistema de carrera que proteja la dignidad de la función municipal y que guarde conformidad con su carácter técnico, profesional y jerarquizado.»

y en su párrafo tercero:

«Las promociones podrán efectuarse, según lo disponga el Estatuto, mediante ascenso en el respectivo escalafón o, excepcionalmente, por concurso...»

De esta manera el reclutamiento se hace para ingresar, no en un puesto concreto, sino en un colectivo jerarquizado que tiene a su cargo la responsabilidad del funcionamiento de un servicio público, y en el que se permanece de por vida ocupando sucesivamente los empleos que ese colectivo tiene reservados y cada vez de mayor importancia, responsabilidad y remuneración. La selección no se hace para un puesto de trabajo, sino para un cuerpo y dentro de él sé hace carrera.

Las principales características del sistema recogido en la Ley son las siguientes:

Primera. Como aludimos anteriormente, el Estatuto habrá de contemplar los derechos y deberes, el ingreso, la responsabilidad administrativa y la cesación de funciones.

No obstante el avance que suponen estas disposiciones respecto del régimen actual parece faltar que no se integren dentro de este Estatuto, el régimen de sindicación y participación de los funcionarios, que debería de incluir, obviamente, el derecho de reunión y el de negociación de las condiciones de trabjo, evidentemente con las peculiaridades que se deban introducir al estar en un sistema estatutario o administrativo y no de Derecho laboral, donde, aquí sí, la negociación colectiva debe adquirir toda su vigencia.

De otro lado no se alude a las posibles situaciones administrativas de los funcionarios, como las excedencias, suspensión de funciones..., recogiéndose tan sólo en el artículo 35.4 la Comisión de Servicios, lo cual parece evidente debiera ser recogido en el futuro Estatuto.

Asimismo, tampoco se hace mención a un sistema de incompatibilidades que asegure la imparcialidad, independencia y efectiva dedicación al servicio público de los funcionarios.

Segunda. En cuanto al ingreso el artículo 33 va a establecer la selección por concurso público garantizando que la selección se efectuará mediante procedimientos técnicos, imparciales e idóneos. 
Este artículo que por fin, recoge el mérito y la capacidad para el acceso a la Función pública, no obstante, debería haber asegurado asimismo la publicidad, a fin de garantizar a la ciudadanía chilena, en general, la posibilidad de acceso a estos cargos públicos, lo cual podría hacerse realidad mediante la obligación de publicar la celebración de las pruebas selectivas en los Diarios Oficiales.

Tercera. La carrera funcionarial, de acuerdo con su artículo 34.2 se basará en tres principios:

a) Mérito

b) Idoneidad

c) Antigüedad.

$Y$ aunque en principio no tenemos nada que oponer a ninguno de ellos sí parecería conveniente que no fuese la antigüedad en el escalafón el elemento que primara para el desempeño de los puestos de trabajo de mayor responsabilidad y así su valoración no debería ser superior a los otros dos elementos.

Cuarta. Esta Ley 18695, va a reconocer, el derecho al cargo y así el artículo 35 va a establecer:

«El personal gozará de estabilidad en el empleo y sólo podrá cesar en él por renuncia voluntaria debidamente aceptada, por jubilación o por otra causa legal basada en el desempeño deficiente, en el incumplimiento de las obligaciones, en la pérdida de requisitos para ejercer la función, en el término del período legal o en la supresión del empleo".

En todo caso este Principio de Estabilidad en el empleo, a fin de ser coherentes con el sistema cerrado de Función pública en el que se inserta debería ser robustecido mediante el sistema de dotar de las suficientes garantías administrativas y judiciales al procedimiento de calificaciones y al sumario administrativo, a fin de no posibilitar una burla de este Principio mediante una apreciación subjetiva del «desempeño de las funciones» o del «incumplimiento de las obligaciones».

Quinta. Coherentemente con el sistema cerrado de función pública que establece esta Ley se va a reconocer el derecho a la capacitación y perfeccionamiento de los funcionarios en su artículo 37. Lógicamente la rigidez del sistema de carrera obliga a una labor adecuada y tenaz de previsión de efectivos, como reconoce LoNG en Documentacion Administrativa núm. 100, y a la creación de ágiles sistemas de gestión en las carreras, que si no se producen impedirán la materialización de las ventajas. 
Sexta. Se va a recoger junto a este sistema de promoción cerrado una excepción, los titulares de los puestos de trabajo de mayor responsabilidad dentro de la estructura municipal:

- Secretaría Municipal.

- Secretaría Comunal de Planificación y Coordinación.

- Otras unidades encargadas de funciones de prestación de servicios, de Administración interna, relacionadas con el desarrollo comunitario, obras municipales, aseo y ornato, tránsito y transporte público, Administración y finanzas, asesoría jurídica y control.

$Y$ si leemos detenida y serenamente el apartado tercero, no son "números clausus», sino que son variadas, amplias y permiten tal discrecionalidad $y / o$ arbitrariedad que en la práctica podrían romper el sistema de carrera arbitrado premiando la fidelidad política o personal.

Parece indudable que éste sea uno de los puntos más negtivos de la presente Ley que prima la confianza sobre el mérito y la idoneidad.

Séptima. Por último, los artículos 39 y 40 terminan con una declaración de intenciones y no son un mandato imperativo asegurando mediante garantías que permitiesen llevarlo a su exacto cumplimiento. Así el artículo 39 habla de "se promoverá y el artículo 40 de "se velará», haciendo referencia estos dos artículos:

- Principio de remuneración según las funciones desarrolladas.

- Principio de igualdad de oportunidades y capacitación y perfeccionamiento de los funcionarios.

En conclusión, habrá que esperar al desarrollo de estas bases en el futuro Estatuto para responder a las preguntas que esta regulación plantea, para poder analizar la carrera administrativa que se diseña, el sistema de retribuciones que implanta, los derechos y deberes que reconoce y establece, el régimen disciplinario que prevé y en general todas aquellas cuestiones que nos determinen si estamos ante una auténtica y decidida reforma del sistema del personal municipal chileno.

\section{CONCLUSIONES}

En síntesis podríamos después del análisis efectuado extraer las siguientes conclusiones:

Primera. La reforma territorial a nivel regional y municipal en Chile obedece a un intento del régimen dictatorial de perpetuar institucionalmente su existencia no descentralizando las estructuras 
administrativas, sino desconcentrando primero y privatizando después las mismas, robusteciendo a la vez el control social y político sobre la ciudadanía.

Segunda. La reforma local chilena contenida en la Ley 18695 no ha asegurado el Principio democrático de elección de los órganos representativos y el Principio de Autonomía de los entes locales, entendiendo este último como la capacidad de gestionar cada ente local sus intereses respectivos sin dependencia jerárquica de otros entes públicos territoriales ya sea el Estado o las Regiones.

Tercera. El Plan de Acción Cívica Nacional revela las intenciones no confesadas públicamente del régimen de no establecer un sistema auténticamente democrático en Chile, sin apellidos, y que potencie el desarrollo de los Gobiernos locales.

Cuarta. Este Plan revela asimismo los deseos de basar la carrera administrativa primordialmente en la fidelidad y sólo en un segundo término en el mérito y la idoneidad, to cual queda atisbado en el artículo 38 de la Ley 18695.

Quinta. No obstante lo anteriormente expuesto, debe reconocerse que en muchos aspectos en general y en el personal municipal, en particular, esta Ley representa un avance evidente, estableciendo Principios y garantías inexistentes hasta ahora.

Sexta. Habrá que esperar, para un auténtico diagnóstico de la reforma del personal municipal chileno, que se dicte el Estatuto para ver si efectivamente los Principios y Garantías recogidos en la Ley 18695 se plasman en un texto armónico y expansivo que permita de una vez por todas tener en Chile una Función pública profesionalizada y moderna.

Séptima. Parece asimismo evidente que debiera incluirse dentro de este Estatuto al personal sanitario y docente transferido a los entes locales, toda vez que entendamos que como servicios públicos esenciales para una comunidad, éstos no deben ser privativos y dejados a la inercia del lucro y del beneficio de la émpresa privada.

Octava. Asimismo, resultaría interesante evaluar las necesidades de personal de los entes locales, a través de estudios que permitiesen conocer en profundidad ¿qué objetivos se persiguen?, y ¿qué medios humanos se necesitan?, a fin de adoptar las plantillas de personal a las necesidades efectivamente existentes en los municipios chilenos.

Novena. Por último, parecería adecuado establecer sistemas de flexibilización del sistema rígido y cerrado previsto en la Ley 18695 acercándose a un sistema mixto que tomase de los sistemas abiertos las posibilidades y perspectivas que éstos ofrecen. 